\title{
Pandemic preparedness and protective clothing: priorities of health care workers in a Canadian teaching hospital
}

\author{
Jorge E. Zamora, MD · Nathan Luyt, MD
}

Received: 8 May 2009/Accepted: 29 May 2009/Published online: 11 June 2009

(C) Canadian Anesthesiologists' Society 2009

\section{To the Editor,}

Emerging infectious diseases are part of the new reality for front-line health care workers (HCWs). ${ }^{1}$ Their input is required when protective clothing policies are drafted. Many respiratory interventions in patients with febrile respiratory illnesses put $\mathrm{HCWs}$ at high risk for disease transmission. During the severe acute respiratory syndrome (SARS) crisis of 2003, 9\% of HCWs in Toronto who were involved with the intubation of SARS patients contracted the disease. ${ }^{2}$ At the time, the Ontario Ministry of Health and Long-Term Care and the US Center for Disease Control and Prevention (CDC) developed protective clothing recommendations for HCWs who were performing aerosol-generating procedures in patients with SARS. At a minimum, they stipulated the use of personal protective equipment (PPE) combined with an N95 mask or the use of a personal protective clothing system that combined higher levels of respiratory protection, such as a powered air-purifying respirator (PAPR).

In this study, a sample of HCWs frequently exposed to aerosol-generating respiratory procedures was surveyed regarding certain aspects of enhanced CDC PPE and a personal protective system consisting of a coverall, enhanced PPE, and a PAPR. ${ }^{3}$ The PPE consisted of a hair cover, goggles (Spartan, Taiwan), face shield (Splash Shield, Uniontown, PA, USA), N95 mask, non-sterile gloves, and a fluid-resistant surgical gown. The PAPR

J. E. Zamora, MD ( $\varangle)$

Department of Anesthesiology, Queen's University,

Kingston, ON K7L 2V7, Canada

e-mail: zamoraj@kgh.kari.net

N. Luyt, MD

Department of Family and Community Medicine, University

of Toronto, Toronto, ON M5T 1W7, Canada comprised an inner and outer layer. The inner layer included a hair cover, goggles, N95 mask, Tyvek ${ }^{\circledR}$ hooded coveralls, high-top shoe covers (Lakeland Industries, Decatur, GA, USA), surgical gloves, and a PAPR power unit and breathing tube $\left(3 \mathrm{M}^{\mathrm{TM}}\right.$, St. Paul, MN, USA). The outer layer included a Tyvek ${ }^{\circledR}$ hood with visor $\left(3 \mathrm{M}^{\mathrm{TM}}\right.$, St. Paul, MN, USA), a fluid-resistant surgical gown, a second pair of surgical gloves, and a second pair of high-top shoe covers. The Institutional Research Ethics Board of the Kingston General Hospital gave their approval for the survey and all participants provided written consent. Fortyfive anesthesiologists and respiratory therapists were surveyed within 1 month of their participation in a personal protective clothing training program and a previous study examining the efficacy of protective clothing systems. ${ }^{4}$ The participants rated the importance of 12 protective clothing variables using a 10-point scale and then ranked their relative importance. The participants then answered seven questions regarding PPE, PAPR, coaching, and training. Summary data are presented as mean rates and ranks.

Based on a $100 \%$ response rate, $91 \%$ of the participants preferred PAPR to PPE. The participants rated the following variables as most important: ability to see $(9.69 \pm 0.63)$, efficacy of protection $(9.67 \pm 0.80)$, risk of self-contamination during removal $(9.51 \pm 0.99)$, maintenance of manual dexterity $(9.40 \pm 0.72)$, and ability to hear $(9.13 \pm 0.92)$. Speed of removal $(5.47 \pm 2.51)$ and cost $(3.91 \pm 2.84)$ were rated as least important (Fig. 1).

All participants indicated that a coach was necessary for PAPR donning, while $91 \%$ thought a coach was necessary for PAPR removal. Thirty-one percent indicated that a coach was necessary for PPE donning, and 36\% felt a coach was necessary for PPE removal. Only one respondent indicated that regular PAPR refresher training was not necessary. Seventy-six percent of respondents indicated 
Fig. 1 Mean rating and ranking $( \pm \mathrm{SD})$ of surveyed variables

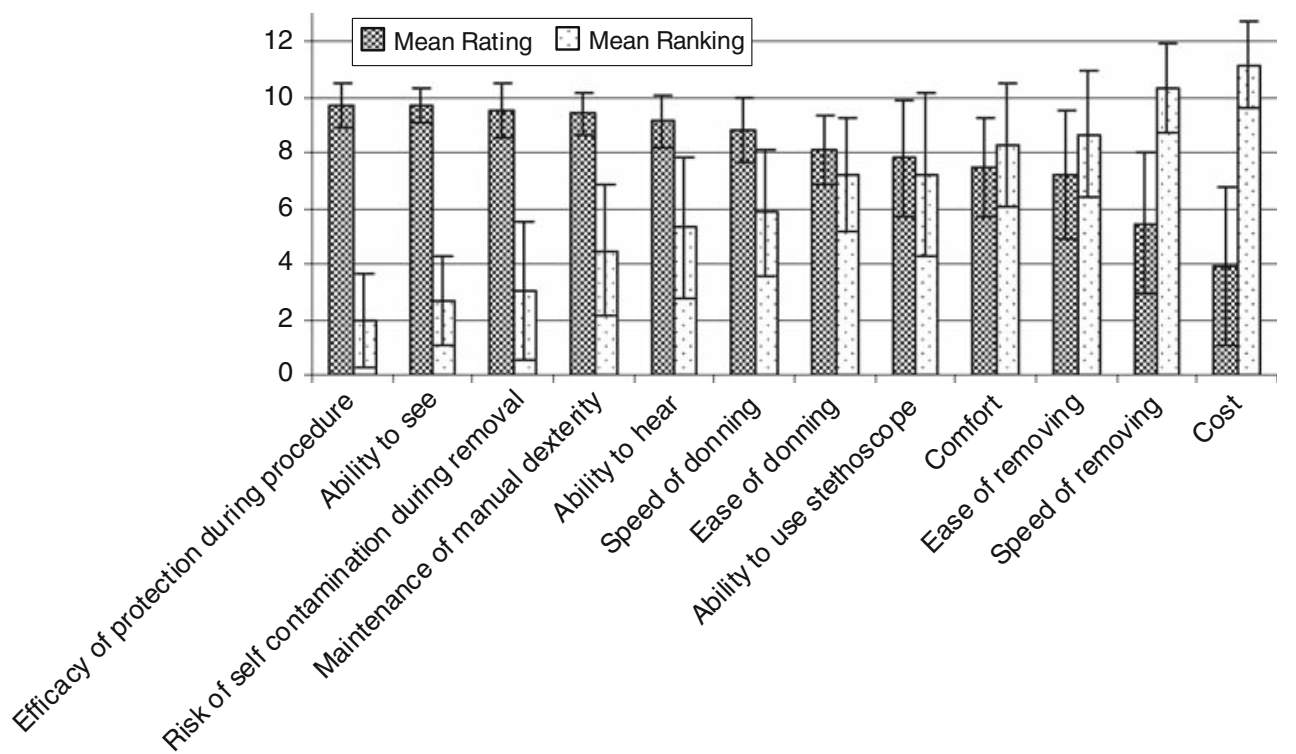

that PAPR refresher training should occur at least annually. In the event of an outbreak, $89 \%$ believed PAPR training should be repeated regardless of the timing of their most recent training. Of these respondents, $15 \%$ indicated that an outbreak in the province of Ontario should prompt retraining; 55\% indicated that an outbreak in Canada should prompt retraining, while $30 \%$ preferred retraining in the event of an outbreak anywhere in the world.

Front-line HCWs believe protective efficacy and the ability to provide patient care are of utmost importance in the selection of protective clothing systems. Factors with less apparent effect on $\mathrm{HCW}$ protection or patient care were felt to be less important. A previous study has shown that the PAPR protective system leads to less contamination of participants' skin and base clothing layers but requires considerably more time for donning than PPE. ${ }^{4}$ The impact of the PPE and PAPR protective systems on the ability of HCWs to perform endotracheal intubation in mannequins has also been studied. ${ }^{5}$ Although total procedure time was longer for participants wearing PAPR, there were no significant differences between the systems regarding either the time required for the intubation component or the participants' ability to successfully perform intubations.

Front-line HCWs preferred the PAPR protective system and believe this system incorporates the qualities they consider most important. Although this system was preferred, it is more complex. Participants indicated that coaching for its donning and removal and periodic retraining in its use are required. These opinions should be considered when decisions are made regarding the most suitable protective clothing system for specific clinical situations.

Funding No funding was received for this study.

Conflicts of interest None declared.

\section{References}

1. Weber SG, Bottei E, Cook R, O'Connor M. SARS, emerging infections, and bioterrorism preparedness. Lancet Infect Dis 2004; 4: 483-4.

2. Caputo KM, Byrick $R$, Chapman $M G$, Orser BJ, Orser BA. Intubation of SARS patients: infection and perspectives of healthcare workers. Can J Anesth 2006; 53: 122-9.

3. Centers for Disease Control and Prevention. Severe acute respiratory syndrome (SARS). Supplement I: Infection control in healthcare, home, and community settings. Available from URL: www.cdc.gov/ncidod/sars/guidance/I/index.htm (accessed May 1, 2009)

4. Zamora JE, Murdoch J, Simchison B, Day AG. Contamination: a comparison of 2 personal protective systems. CMAJ 2006; 175 : 249-54.

5. Murdoch J, Meunier B, Patterson L, Simchison B, Zamora J. The effects of a personal protection system on the performance of a simulated endotracheal intubation. Can J Anesth 2006; 53: 26399 (abstract). 